\title{
The Many Possible Roles of Opioids and Related Peptides in Stress-Induced Analgesia ${ }^{a}$
}

\author{
HUDA AKIL, ELIZABETH YOUNG, \\ J. MICHAEL WALKER, ${ }^{b}$ AND STANLEY J. WATSON \\ Mental Health Research Institute \\ Department of Psychiatry \\ University of Michigan \\ Ann Arbor, Michigan 48109 \\ ${ }^{b}$ Psychology Department \\ Brown University \\ Providence, Rhode Island 02912
}

The potential role of opioids in analgesic brain mechanisms has consistently been a matter of debate. In the last decade, the debate has shifted from whether there are opioid mechanisms of analgesia to the exact nature of these opioid mechanisms. In this, as in many other cases of biology meeting psychology, the task is made more arduous by the intrinsic and well known difficulties inherent in studying pain on the one hand, and by the newly discovered complexities of opioid biology on the other.

We shall discuss the role of opioids in pain regulation in general, and then report on some specific effects of stress on pituitary and brain opioids. In the first section, we shall briefly describe the potential role of two endogenous opioid families in pain modulation. The two families, pro-opiomelanocortin and prodynorphin, produce distinctly different effects on pain responsiveness, may interact with varying opioid and non-opioid receptors in brain, have unique hormonal roles of potential importance to stress and coping, and contain nonopioid peptides also capable of modulating pain. In contrasting them, we hope to reveal to the reader the range of possible roles that these two families may play in pain regulation in general and in stress-induced analgesia in particular. This is not to say that pro-en kephalin products are not relevant to this discussion. We are not considering them here primarily because they are likely to be even more complex in their roles, in view of their widespread anatomy and of the presence of seven distinct opioid cores within their precursor.

The second section of the paper will be concerned with the actual effect of stress on $\beta$-endorphin and related peptides in pituitary and in brain. In this section, we shall not attempt to prove that $\beta$-endorphin is the key to opioid stressinduced analgesia. Rather, we hope to convey to the reader the importance of understanding the cell biology and its regulatory dynamics in attempting to link

\footnotetext{
${ }^{a}$ Supported by National Institute of Drug Abuse Grants DA02265 and DA00254, and by the Theophile Raphael Fund. E. Young is the recipient of Research Career Development Award \#MH00427.
} 
this or any opioid peptide to the production of stress-induced analgesia. Our efforts to understand the $\beta$-endorphin stress interface have led to some insights into regulatory strategies of peptidergic systems, and point to possible new approaches in studying the problem. The discussion, therefore, is more speculative and future oriented as it focuses on these possible directions.

\section{PRO-OPIOMELANOCORTIN AND PRO-DYNORPHIN PRODUCTS: OPIOID AND NON-OPIOID EFFECTS ON PAIN RESPONSIVENESS}

The existence of three opioid precursors was fully established in 1982 , when the full sequences of the pro-hormones for pro-opiomelanocortin, the enkephalins, and dynorphins/alpha neo-endorphin were established using recombinant DNA tools that elucidated the messenger RNA structure., The first precursor that had been elucidated was pro-ACTH/ $\beta$-endorphin otherwise known as proopiomelanocortin or POMC. ${ }^{3}$ The structures of the precursors, their homologies, detailed anatomy, and post-translational processing have been recently reviewed. ${ }^{4}$

For the purposes of the present discussion, we remind the reader that POMC contains the full sequence of ACTH (adrenocorticotropin hormone), as well as that of $\beta$-endorphin 1-31, and three repeats of the ACTH 4-10 core. POMC is present in the pituitary anterior lobe corticotrophs, in every cell of the pituitary intermediate lobe, and in two distinct cells in the brain. The major cell group is in the hypothalamic arcuate nucleus, projecting rostrally to the septal area and caudally through medial thalamus to the midbrain central grey. The smaller cell group, found in the nucleus tractus solitarius (NTS), was first described by Schwartzberg and Nakane ${ }^{5}$ and confirmed by a number of groups. ${ }^{6}$ Its projectional pathways rostrally and caudally are yet to be fully described.

Pro-dynorphin contains three active opioid cores all beginning with the leucine-enkephalin sequence followed by unique carboxy-terminal extensions. The three opioid sequences are known as neo-endorphin, ${ }^{7}$ dynorphin $\mathrm{A}^{8}$ and dynorphin B or rimorphin. ${ }^{9,10}$ Pro-dynorphin is expressed in multiple cell groups in the brain including several associated with pain-modulating structures, such as the dorsal horn of the spinal cord, the periaqueductal grey area, and cortex. Prodynorphin is also found in the magnocellular hypothalamic groups that synthesize vasopressin, project to the posterior lobe of the pituitary, and modulate anterior lobe corticotrophs (those same cells that make and release POMC). The anatomy of pro-dynorphin and its comparison to pro-enkephalin were also summarized. ${ }^{6}$

\section{Pro-Opiomelanocortin and Analgesia}

\section{Electrical Stimulation of Brain POMC Systems}

Of the numerous naturally including opioids (over twelve identified forms in brain), $\beta$-endorphin produces the most clear-cut and longest lasting opiate analgesia. Its analgesic potency is evident with the unmodified peptide, requiring no efforts to stabilize it against enzymatic degradation in vivo. This observation, coupled with the fact that POMC pathways course along classical limbic and 
pain-modulating structures (e.g. medial thalamus and periaqueductal grey area), has led us and others to focus on the potential role of $\beta$-endorphin in endogenous analgesia.

One of the most obvious questions is whether electrical stimulation of $\beta$ endorphin systems in the brain produces analgesia. The results are interestingly mixed. Electrical stimulation along the midbrain POMC bundle produces profound analgesia, which is partially reversible by naloxone. Indeed, the overlap between that bundle and the independently described sites for stimulationproduced analgesia is quite remarkable. ${ }^{11}$ However, stimulation of the arcuate cell group does not produce analgesia, a finding that remains unexplained. More recently, we have found that electrical stimulation of the nucleus tractus solitarius, a structure which expresses all three opioid precursors, produces clearcut, naloxone-reversible analgesia (Lewis et al., in preparation). Whether this is due to the sole action of POMC products or to a combination of opioids released from this structure remains to be determined.

\section{The Many POMC-Derived Peptides in Brain}

While a potential role for $\beta$-endorphin in modulating nociception is easy to accept, the question arises as to the possible functions of the peptides that are cosynthesized with $\beta$-endorphin. As mentioned above, the precursor codes for ACTH and for a 16,000 dalton amino-terminal peptide that contains a structural homology with ACTH 4-10. The region of the N-terminal peptide that contains this homology has been termed gamma-MSH. Do ACTH and gamma-MSH play a role in nociception? While apparently simple, this question is closely related to the issue of post-translational processing of POMC in brain. It is well known that the same precursor, POMC, gives rise to distinctly different peptide products depending on the cells that express it. Thus, in the anterior lobe, the precursor yields $\beta$-endorphin $1-31, A C T H$, and the full $\mathrm{N}$-terminal protein. In the intermediate lobe, however, these products are further modified to yield shorter, more processed peptides with unique biological activities, such as the opiateinactive $\mathrm{N}$-acetyl- $\beta$-endorphin $1-27$, and the ACTH product alpha-MSH, which is devoid of steroidogenic activity. ${ }^{4}$

Thus, the issue of the potential role of brain POMC products in brain is closely intertwined with the question of what is really made in the brain by the POMC neurons. Unfortunately, the answers are not all in on this question. It is becoming clear that $\mathrm{N}$-acetylation of $\beta$-endorphin occurs only to a small extent in the hypothalamus and along the arcuate projection pathway (H. Akil, unpublished data). On the other hand, $\beta$-endorphin 1-31 becomes converted to $\beta$ endorphin 1-27 quite actively, with more conversion becoming evident as one proceeds from hypothalamus to central grey regions. In the midbrain, there are almost equal parts of $\beta$-endorphin 1-31 to $\beta$-endorphin 1-27 (H. Akil, unpublished data). ${ }^{12.13}$ It should be noted that $\beta$-endorphin 1-27 is still an active opioid although its affinity at the mu and delta opiate receptors is appoximately ten times lower than is seen with $\beta$-endorphin $1-31 .^{14}$ Furthermore, its analgesic activity is also substantially decreased relative to $\beta$-endorphin $1-31 .{ }^{15}$

Within the arcuate system, one can detect small amounts of ACTH, but the predominant product from this region is ACTH 1-13 amide (or non-acetylated alpha-MSH). ${ }^{16}$ The fate of the $\mathrm{N}$-terminal peptide is not well delineated in rat brain. 
The second POMC-producing cell group is found in the NTS; it produces the same peptides as the arcuate system, plus their $\mathrm{N}$-acetylated counterparts. Thus one can find significant amounts of $\mathrm{N}$-acetylated forms of $\beta$-endorphin 1-31 and $\beta$-endorphin 1-27, which are not active at the opioid receptor, along with their non-acetylated opioid active counterparts. ${ }^{37}$ Similarly, one can find both alphaMSH and its non-acetylated form.

It is unclear at this point whether brain cells release all these peptides in proportions identical to their stored levels. Our results to date (see below) argue that this may not be the case. It is entirely conceivable that a given POMC cell would release $\beta$-endorphin 1-27 under some circumstances, and $\beta$-endorphin 131 under others. It is also quite likely that it would co-release ACTH, alpha-MSH, or des-acetyl-alpha-MSH alongside the opioids. Finally some form of the Nterminal gamma MSH region may also be liberated. The exact conditions that may lead to a particular combination of peptide products at the synapse are yet to be explored. It is clear however, that the cell has a great deal more latitude than previously anticipated, and that its output may change as a function of recent or long term history (see below). Thus, the following description of the pharmacological actions of POMC products should be seen as exploring the possibilities, rather than revealing an ultimate truth about POMC products modulating nociception.

\section{Modulation of Pain by Non-Opioid Products of POMC}

We can now return to our question as to the possible role of other POMC products in modulating nociception. The exact role of $\mathrm{N}$-acetylated and shorter forms of $\beta$-endorphin in pain control has scarcely been addressed, possibly because the nature of $\beta$-endorphin forms in brain has been, until recently, a matter of debate. Interestingly, C. H. Li and his colleagues ${ }^{38}$ have suggested that the less active forms of $\beta$-endorphin might act as antagonists to analgesia. A likely explanation is that they may act as weak partial agonists, which are recognized by the relevant opioid receptor or receptors, producing long-lasting occupancy because of their hydrophobicity, with little efficacy. These notions are clearly worthy of being pursued at the physiological level, since the idea that two products derived from the same neuron may exhibit checks and balances between them is unusual and appealing.

The potential role of $\mathrm{ACTH}$ and its products in nociception is also likely to be complex. While there are several reports that intraventricular injection of ACTH can diminish opiate analgesia or produce hyperalgesia, we have found that, within the central grey, ACTH can be an analgesic with a potency equivalent to morphine. ${ }^{17}$ Furthermore, ACTH-derived products, such as alpha-MSH and ACTH 1-13 amine (the predominant ACTH-like peptide in hypothalamus) also produce reliable analgesia when micro-injected in the midbrain central grey.

Finally, gamma-MSH, the potential peptide derived from the $\mathrm{N}$-terminal domain of POMC, does not produce analgesia, but produces substantial potentiation of the ACTH-induced analgesia. ${ }^{17,39}$ These observations, coupled with several more on the additivity of sub-analgesic doses of $\beta$-endorphin and ACTH peptides, have suggested to us that POMC products, when released into the periaqueductal grey, may exhibit co-ordinate actions all leading to pain inhibition. ${ }^{40}$ This is not to say however that these actions may not be self-limiting; indeed antagonistic or partially agonistic effects may play a critical physiological 
role against the potentially long-lasting effects of $\beta$-endorphin 1-31-induced analgesia.

It is evident from the above overview that POMC in brain can give rise to numerous peptides with both opioid and non-opioid properties and analgesic and non-analgesic properties. It is therefore not surprising that stimulation of POMC cells does not always produce analgesia and that the analgesia elicited from stimulating POMC systems in the brain is not always fully naloxone reversible.

\section{Pro-Dynorphin and Analgesia}

Pro-Dynorphin-derived products provide an interesting contrast with $\beta$-endorphin vis- $a$-vis analgetic profiles. While $\beta$-endorphin micro-injections yielded readily recognizable, potent opiate analgesia, the administration of dynorphin $A$ has resulted in a much more complex pattern of results. In our own hands, and in those of other investigators, initial attempts to demonstrate analgesia with dynorphin A were largely negative, regardless of whether the peptide was administered intracerebroventricularly or within the central grey. ${ }^{18}$ On the other hand, investigators have obtained analgesia by intrathecal injection. ${ }^{19}$ The lack of supraspinal analgesia was surprising in view of the great potency of dynorphin in vitro. The most obvious interpretations were either in terms of rapid breakdown of dynorphin A, or in terms of its possible interactions with a unique receptor subtype, the kappa receptor. Since there was a suggestion in the literature that kappa-induced analgesia may be more evident at the level of the spinal cord rather than supraspinally, a number of groups have given dynorphin $A$ intrathecally, at the level of the spinal cord, and have observed very long-lasting inhibition of withdrawal reflexes, sometimes likened to a paralysis. ${ }^{19}$ Meanwhile, Lee and her colleagues ${ }^{20}$ showed that dynorphin-induced analgesia can in fact antagonize morphine analgesia, and suggested possible interactions between multiple opioid receptor subtypes.

Our own work led us to propose a somewhat different interpretation for the same observation, and for a number of other behavioral paradoxes seen with dynorphin $\mathrm{A}$. We ${ }^{21,22}$ showed that when the amino-terminal tyrosine is removed from dynorphin A (yielding dynorphin 2-17 or des-tyrosine dynorphin), it loses, as expected, its ability to interact with opioid receptors. However, dynorphin 2-17 continues to exhibit a number of behavioral and electrophysiological effects, identical to those seen with dynorphin A 1-17, and is, of course, not naloxone reversible. Most relevant to this discussion, dynorphin A 2-17 can also produce an antagonism of morphine analgesia, shifting the dose-response curve to the right ${ }^{23}$ We therefore suggested that dynorphin A may contain two active cores, the classic opioid core encoded by the leucine-enkephalin sequence followed by a carboxy-terminal extension, and a second, non-opioid core, which we believe resides primarily at the amino terminus, beyond position 9. (This conclusion is based on some preliminary structure-activity studies). Interestingly, Herz's group ${ }^{24}$ at the Max Planck Institute has shown that the spinal cord analgesia induced by dynorphin A can be mimicked by the non-opioid dynorphin 2-17.

Recent work in our laboratory ${ }^{25}$ using coupled reverse-phase HPLC with

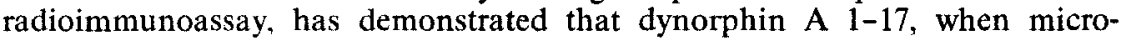
injected into the central grey, is rapidly converted to dynorphin A 2-17. This latter 
product is then stable enough to be detected by radioimmunoassay following sacrifice, dissection, and extraction of the peptides. This finding suggests that the unique and non-naloxone reversible effects seen upon dynorphin A administration are not due to interaction with the kappa receptor, but rather with a unique non-opioid receptor that recognizes dynorphin A 2-17. Whether dynorphin A 2-17 occurs naturally and is stored in synaptic vesicles is currently under study. We also do not know whether dynorphin $\mathrm{A}$, when released naturally, is accorded sufficient protection within the synapse to interact with the opioid receptors at that junction.

We should mention that dynorphin A 1-17 is not always the dominant form of that peptide in brain. Weber and co-workers ${ }^{26}$ have reported that dynorphin A 18 , previously identified by Seizinger et al. ${ }^{27}$ is the more dominant form in rat brain. Our findings suggest that there is a great deal of regional and species differences in the ratios of dynorphin A 1-17 and dynorphin A 1-8. ${ }^{28}$ Thus, within rat brain the substantia nigra stores almost exclusively dynorphin A 1-8 whereas the nucleus tractus solitarius has a predominance of dynorphin A 1-17. Since dynorphin A 1-17 and dynorphin A 1-8 exhibit differences in their opioid profiles $^{29}$ and since the former may contain the non-opioid core while the latter may not, it becomes important to understand which peptide form is released in which regions.

Thus, while there is little work on the other opioid and non-opioid regions of pro-dynorphin with regard to pain regulation, the study of the dynorphin $A$ region reveals the same range of complexities seen with POMC. While we are dealing with two different families, with different anatomies, with opioid products that have different opioid receptor preferences, we are struck with the same overall pattern: In both cases, we can have opioid and non-opioid peptide products, both capable of modulating pain in a complex fashion, sometimes leading to analgesia, and sometimes counteracting that analgesia.

The study of POMC and pro-dynorphin products and their role in pain modulation does not allow one to pre-select a system most likely to be implicated in stress-induced analgesia-or any other endogenous pain regulatory response. We suspect that consideration of pro-enkephalin peptides and their role in nociception would lead to very similar conclusions. However, the behavioral studies, in conjunction with the information on multiple peptide forms, have given us a sense of the richness of these systems, and their capacity to fine-tune pain responsiveness in ways not previously suspected by us. The opioid systems are apparently capable of bringing to bear the actions of multiple co-synthesized products on pain inhibition, as well as producing and releasing peptides that may terminate, reverse, or prevent this analgesia.

We cannot overemphasize, however, that such pharmacological and metabolic studies only give us a glimpse of "possible scenarios." A true understanding of what happens in brain when analgesia is produced requires a more complete knowledge of which systems are activated, which combinations and forms of peptides are release, their eventual fate at the synapse, and the array of opioid and non-opioid receptors they encounter and activate. This is clearly a tall order, rendered more discouraging by the fact that most of us have been unable to discern consistent changes in brain opioid peptide contents following various stressors. Thus, the answer to even the first and most basic of questions-which systems are activated-is not at hand. The following section describes our efforts to show that $\beta$-endorphin systems are activated by a stressor that activates opioid analgetic mechanisms. 


\section{THE EFFECT OF FOOTSHOCK STRESS ON $\beta$-ENDORPHIN IN PITUITARY AND IN BRAIN}

The initial studies on changes in opioid levels following various stressors emphasized measurements of steady-state levels following the first stressor. The results were generally variable across laboratories, substances, and assays, although a number of groups suggested a change in opioid levels following stressinduced analgesia. ${ }^{4}$ Even within our own laboratory, we have occasionally found increases in $\beta$-endorphin content or decreases, depending on the exact timing of the measurements following the stressors. It became evident that measurement of peptide content in a particular brain region was not sufficient to implicate a particular opioid in stress-induced analgesia. Even if one found a change, its interpretation would be problematic. Does an eventual increase in content signify overall activation of the system, leading to increases in the stores of peptides, or does it point to the opposite explanation, i.e., a decrease in activation and release? Such practical and conceptual problems indicated to us the need to address the issue of opioid changes that accompany stress in a more dynamic framework. It became apparent that we needed to understand the regulatory biology of opioid cells in order to evolve strategies for measuring dynamic changes following stress or any other environmental manipulation.

Thus, we undertook a series of studies that focused on the effect of acute and repeated footshock on the cell biology of the $\beta$-endorphin/ACTH system in both pituitary and brain. We focused on $\beta$-endorphin for a number of reasons, including the fact that it is likely to be involved in stress responsiveness given its close association with ACTH, the fact that it may play a role in analgesia given its pharmacological potency in regulating pain, and the fact that its brain anatomy is relatively simpler than that of the other two families, allowing more discrete dissection of cell groups and target areas. We studied the pituitary for two reasons: it is a tissue particularly rich in POMC, which could be more easily subjected to biosynthetic studies and some researchers had suggested that stress-induced analgesia may in fact be mediated, at least partially, by activation of pituitary endorphins ${ }^{30}$ Furthermore the pituitary of rat contains two distinct tissues that express POMC, the anterior lobe and the intermediate lobe. Since the anterior lobe corticotrophs are classically thought to be responsive to stress, while the role of the intermediate lobe in stress is unclear, this would permit us to study two POMC cell types with unique POMC processing, with possibly varying degrees of stress responsiveness. It was our hope that we could learn from the pituitary studies in order to generalize to brain.

In all the studies to be described below the same stress paradigm was employed in male, adult, Sprague-Dawley rats. The conditions of the footshock are similar to those previously shown to produce opioid analgesia. ${ }^{31-33}$ Each study included four groups of animals: (1) a control group, unstressed and unhandled; (2) an acute stress group that receives a 30 minute session of intermittent footshock immediately prior to sacrifice; (3) a chronically stressed/rested group that was subjected to a daily, 30 minute session of footshock for 14 days followed by 24 hours of rest prior to sacrifice; and (4) a chronically stressed/acutely stressed group that was repeatedly stressed for 14 days and stressed immediately prior to sacrifice. It should be noted that, while acute stress resulted in analgesia, repeated stress appears to engender a tolerance such that a chronically stressed/acutely stressed animal exhibits no analgesia. ${ }^{31,32}$ 


\section{Stress Effects on Anterior Lobe POMC}

As expected, acute footshock stress leads to substantial elevations of ACTH, $\beta$ endorphin, and corticosteroids in the plasma of the stressed rats. ${ }^{34}$ Simultaneously, the content of the anterior lobe decreases by approximately $20-25 \%$ relative to control values. Repeated stress, as given to the chronically stressed/ rested group, leads to a substantial increase in the content of $\beta$-endorphin in the anterior lobe (approximately $300 \%$ of control). Yet the resting plasma levels in that group are indistinguishable from controls. When this chronically stressed group is re-challenged with acute stress, there is a substantial drop in anterior lobe content relative to the chronically stressed/rested levels. However, the plasma peptide and steroid levels appear very similar to the acutely stressed group. Thus, there is an apparent discrepancy between what the plasma levels indicate and what is happening at the level of the anterior lobe. Measurement of the circulating hormones alone would have led us to conclude that the system responds in an identical fashion after the fifteenth stressor as it did after the first-normal resting levels, similar stress responses. Yet, the results of measurement of gland content suggest that this is being achieved in dramatically different ways as function of the animal's history.

The most evident change is that the stored levels are substantially higher in the chronically stressed rats. This suggests a change in the long-term steady-state levels of POMC. The most likely explanation for such a change in stores, in the face of repeated activation and release, is an increase in biosynthesis at the level of transcription and translation. Indeed, measurement of the messenger RNA (mRNA) specific to POMC using a specific mouse cDNA probe (courtesy of Dr. James Roberts, Columbia University) has demonstrated a $50 \%$ elevation in anterior lobe POMC message following chronic stress. ${ }^{40}$ Thus, the anterior lobe corticotrophs appear to have responded to the repeated demand by having more of the POMC message available for translation. Whether this was achieved by an increase in the rate of gene transcription or a change in the stability of the mRNA is not yet determined. Regardless, more peptides are made and stored. Furthermore release studies in these animals show that in chronically stressed rats ACTH and POMC are highly releasable. ${ }^{34}$ Thus, chronic stress appears to lead to a specific increase in stores and in the releasable pool of POMC products.

The question remains, what happens following the first acute stress? Why does the depletion in anterior lobe stores appear minimal, even though the same levels of hormones are achieved in plasma? A possible answer to these questions were derived from work on the biosynthesis of POMC in short-term cultures immediately following stress. ${ }^{35,40}$ In these studies, the anterior lobe was dissected away from the neurointermediate lobe and a cell suspension was produced that was maintained for a few hours to obtain an index of biosynthetic rates. This was done by using a pulse-chase paradigm followed by purification of POMC products on immunoaffinity columns. The results of these studies can be summarized as follows: In a control rat, approximately 15 minutes are required to synthesize POMC de novo in these cultures. This POMC is converted to its products ( $\beta$-lipotropin and $\beta$-endorphin for the COOH-terminal domain) with an apparent $t_{1 / 2}$ of approximately 32 minutes. Following acute stress, the rate of conversion of POMC to its products becomes accelerated, with an apparent $t_{1 / 2}$ of approximately 16 minutes. Furthermore, after 15 minutes of labeling, $50 \%$ more POMC is made in the acutely stressed lobes as compared to the controls. Note 
that this latter increase cannot be due to an increase in mRNA since that remains unchanged after acute stress (the time is too short for a significant change in the message pool). One must presume that whatever mRNA is available to these cells has become translated more efficiently. In turn, the POMC thus formed is more rapidly processed into its products. The net effect is an acceleration in biosynthesis after acute stress that relies on increased efficiency of co-translational and post-translational mechanisms. Interestingly, in the chronically stressed/rested animals, which had a threefold increase in stored POMC products, the rate of POMC conversion to its products was not elevated. On the contrary, it was somewhat slower than control, with an apparent $t_{1 / 2}$ of 40 minutes. 35,40

Thus, there appears to be two mechanisms of regulation of anterior lobe POMC that become evident following our stress paradigm: a short term mechanism that is apparently triggered by release of the peptide hormones and involves more efficient handling of the precursor/product conversion, and a longer term mechanism that involves an increase in mRNA for POMC. The two appear to occur at different times for the organism and result in differences in rates of biosynthesis and releasability of the stores. It should be noted here that the short-term effect (i.e., increase in biosynthesis immediately following release) would tend to replenish the stores of peptides as they become depleted by stimulation. Thus, it is not uncommon that with mild stress, no change in content of anterior lobe ACTH/ $\beta$-endorphin can be detected, in spite of substantial elevation in plasma hormone levels. It is likely that a similar mechanism may operate in brain and mask changes in peptide levels following stimulation of a peptidergic pathway.

\section{Stress Effects on Intermediate Lobe POMC}

The effects of the stress paradigm on the intermediate lobe have recently been described ${ }^{36}$ and will only be summarized here. Our studies in the intermediate lobe have led us to the following conclusions. (1) Following acute stress there is a small but reliable response from the intermediate lobe as evidenced by an increase in plasma $\alpha-\mathrm{MSH}$ and $\mathrm{N}$-acetyl- $\beta$-endorphin, which are exclusively intermediate lobe products. Interestingly, content of POMC products in the intermediate lobe remains unchanged. (2) Following chronic stress, the intermediate lobe becomes induced, exhibiting more POMC-specific mRNA, (unpublished data), more stored POMC products, and more releasable stores. ${ }^{36}$ (3) There is evidence of an increase in processing coupled to release, as was seen in the anterior lobe. However, since the material in the intermediate lobe becomes increasingly more releasable with repetition, the change in $t_{1 / 2}$ is more evident in chronically stressed rats.

Studies in the intermediate lobe generally confirm the general conclusions drawn from the anterior lobe results-that these cells have multiple mechanisms of regulation, triggered by changes in demand, resulting in changes in posttranslational events as well as changes in the overall biosynthetic capacity of the system as marked by the amount of mRNA and the total stores.

\section{Which is the Real Product?}

A main issue that the pituitary studies have allowed us to address is that of a strategy for determining "the" products that are released among a host of 
possibilities. As mentioned earlier in this chapter, the anterior lobe stores more $\beta$-lipotropin $(\beta-\mathbf{L P H})$ than it does $\beta$-endorphin. Which of these is released? Are they released in ratios equivalent to what is stored? Similarly, the intermediate lobe contains at least five different forms of $\beta$-endorphin, the most dominant form being $\mathrm{N}$-acetyl- $\beta$-endorphin 1-27. Is this the most important product of the intermediate lobe? Such questions are intrinsically important and relevant to the question of a potential role of peripheral $\beta$-endorphin-like peptides in mediating stress-induced analgesia. Further, they have implications for the brain studies, since multiple peptide forms exist in the brain. However, release studies in brain tissue are substantially more difficult.

It was thus our hope to derive a criterion by which a peptide form could be construed as the major releasable product of a given cell. Is this determined by stored ratios? Is the most processed form the most readily releasable? Is the most biologically active peptide the one to focus on, while the others can be seen as metabolites? These issues were addressed within the context of the above studies by examining which peptide forms were specifically altered by stress, were released into the blood stream, or were changed the most obviously by the regulatory mechanisms we have described.

We have learned that a product is not necessarily the most abundantly stored peptide form. For instance, we see a higher release of $\beta$-endorphin than $\beta$-LPH in plasma, ${ }^{41}$ in spite of the fact that $\beta$-LPH is more abundant in the anterior lobe. ${ }^{13}$ Similarly, we have observed a selective release of $N$-Acetyl- $\beta$-endorphin 1-31 following chronic stress, in spite of the fact that it is not, normally, the most abundant form in the intermediate lobe. ${ }^{36}$ Nor does opioid potency appear to be a relevant criterion, since the $\mathrm{N}$-acetylated peptides are not opioid active. Finally, while $\beta$-endorphin is more processed than $\beta$-LPH and appears more releasable, $\mathrm{N}$-acetyl- $\beta$-endorphin $1-31$ is not the most processed form in the intermediate lobe. Thus, none of the criteria stated above appeared to allow us to predict which of the many sizes and forms of $\beta$-endorphin-like peptides would be selectively treated as the cell's major product.

However, we have been able to derive a correlate of releasability. To date, it appears that the more releasable products are more clearly regulated by the parent cells. For example, if we compare changes in $\beta$-endorphin to the simultaneous changes in POMC as we move through the stress paradigm, it is apparent that $\beta$-endorphin is more clearly depleted following acute stress, most clearly enriched in the chronically stressed/rested animal, and again more clearly depleted upon re-challenge. A similar situation holds for $\mathrm{N}$-acetyl- $\beta$-endorphin $1-31$ in intermediate lobe. Hence, a possible criterion for a highly releasable product is that it be selectively regulated as a function of changing cellular demands, particularly being selectively enriched and sequestered upon a chronic increase in demand.

A note of caution, however: It is conceivable that the product is different as a function of the animal's recent history, e.g., we have preliminary evidence suggesting that this may be the case in anterior lobe, when the ratio of $\beta$-LPH: $\beta$ endorphin released rises following chronic stress-possibly because of the deceleration of processing noted above (Young \& Akil, unpublished data).

The pituitary studies let to some insight in the regulatory mechanisms employed by endocrine POMC cells, revealing both short-term and long-term strategies available to these systems. Furthermore, they suggested an index for focusing on a particular peptide form as likely to be highly releasable. Interestingly, they did not lend strong support to the idea of pituitary $\beta$-endorphin playing an important role in stress-induced analgesia. While we have clear 
evidence of an elevation in circulating $\beta$-endorphin following acute stress, $\beta$ endorphin levels are at least equally high in the chronically stressed/acutely stressed rats, which exhibit a tolerance to the analgetic property of footshock stress.

\section{The Effect of Footshock Stress on Brain/ $\beta$-Endorphin}

As mentioned above, acute footshock does not lead to reliable changes in midbrain $\beta$-endorphin levels. On the other hand, repeated footshock followed by a 24 hour rest resulted in a $30-50 \%$ elevation in $\beta$-endorphin immunoreactivity, a finding that parallels what we have observed in the two pituitary lobes. This suggests to us that the system has been induced to form more mRNA as we observed in the gland, but this hypothesis awaits confirmation. Finally, when the chronically stressed rat is re-stressed acutely, there is a measurable decrease in the midbrain $\beta$-endorphin total levels.

Since we were unable to carry out pulse-labeling studies in the brain because of their technical difficulties, we studied the forms of $\beta$-endorphin like material under the four conditions. It should be stated here that in the control rat midbrain we observe a ratio of 1:0.6 in materials the size of $\beta$-endorphin $1-31$ and $\beta$ endorphin $1-27+1-26$, respectively, which shows that most of the material is full sized but a substantial proportion is cleaved at the COOH-terminal.

Following acute stress, the proportions are not substantially altered. However, following chronic stress shorter, more processed forms accumulate selectively ( $\beta$ endorphin 1-31: $\beta$-endorphin 1-27+1-26 is $1: 1.5$ ).

It appears as though the system is not simply generally induced, but that there is a shift in the overall profile leading to greater accumulation of these highly processed products. Upon re-challenge with acute stress, the chronically stressed rats show a return to normal profile of ratios as if the smaller peptides $(\beta-$ endorphins 1-27 and 1-26) have become selectively released ( $\beta$-endorphin 1-31: $\beta$ endorphin 1-27 is 1:0.6 in the chronic/acute group).

Our data lead us to a number of tentative conclusions. (1) Even though we cannot see the effect of footshock stress using acute stress, it is likely to have an impact on brain POMC, since it results in an induction of the system upon repetition. It is likely that the content does not change acutely because of an acceleration of biosynthetic efficiency as seen in the pituitary. (2) The composition of stored products is significantly altered in the chronically stressed rat as compared to the control (more processed opioid peptides are stored). (3) It is quite likely that the chronically stressed rat when re-challenged releases the shorter peptides. These are clearly relatively inactive as compared to $\beta$-endorphin 1-31. They have 10-20-fold lower analgesic potency if not acetylated and no analgesic potency if acetylated. ${ }^{15}$ (4) The main open question is this: Does $\beta$-endorphin 1-31 ever get released in the midbrain? Is it released upon the first stressor but not the fifteenth (where the less active products may be liberated)? If this were the case, we would have a possible mechanism for the behavioral tolerance we observe, as we would be releasing different products on different occasions.

\section{CONCLUSIONS AND FUTURE DIRECTIONS}

The studies outlined above suggest a richer and more complex role of endogenous opioids in the regulation of pain in general, and in stress-induced 
analgesia in particular. They also point to the importance of determining what is released in brain and which opioid and non-opioid receptors are occupied and activated. To this end, it may be critical to devise strategies for determining occupancy of specific receptors after a particular treatment. Preliminary results from our group ${ }^{42}$ suggest the feasibility of such an approach. This, coupled with the study of these peptides at the cell biological and anatomical levels, should enable us to answer our original question: Which opioid systems become activated by stress and are responsible for opioid analgesia?

\section{ACKNOWLEDGMENT}

The authors would like to thank Ms. Adele Henry for manuscript preparation.

\section{REFERENCES}

1. Kakidani, H., Y. Furutani, H. Takahashi, M. Noda, Y. Morimoto, T. Hirose, M. ASAI, S. INAYAMA, S. NAKANISHI \& S. NUMA. 1982. Cloning and sequence analysis of cDNA for porcine beta-neo-endorphin dynorphin precursor. Nature 289:245.

2. Noda, M., Y. Furutani, H. Takahashi, M. Toyosata, T. Hirose, S. Inayama, S. NAKANISHI \& S. NuMA. 1982. Cloning and sequence analysis of cDNA for bovine adrenal proenkephalin. Nature 29:202-206.

3. Nakanishi, S., A. Inoue, T. Kita, M. Nakumura, A. C. Y. Chang, S. N. Cohen \& S. NuMA. 1979. Nucleotide sequence of coned cDNA for bovine corticotropin-beta lipotropin precursor. Nature 274:423-427.

4. Akil, H., S. J. Watson, E. Young, M. E. Lewis, H. Khachaturian \& J. M. Walker. 1984. Endogenous opioids: Biology and function. Ann. Rev. Neurosci. 7:223-255.

5. SChWARTSBERG, D. G. \& P. K. NAKANE. 1983. ACTH-related peptide containing neurons within the medulla oblongata of the rat. Brain Res. 276:351-356.

6. Khachaturian, H., M. E. Lews, M. R-H. Schafer \& S. J. Watson. 1985. Anatomy of CNS opioid systems. Trends Neurosci. 8:111-119.

7. Kargowa, K, N. Miromiro, N. Chino, S. Sakakibara \& Matsuo. 1981. The complete amino acid sequence of alpha-neo-endorphin. Biochem. Biophys. Res. Commun. 99:111-117.

8. Goldstein, A., S. Tachibana, L. E. Lowney, M. Hunkapiller \& L. Hood. 1979. Dynorphin-(1-3), an extraordinarily potent opioid peptide. Proc. Natl. Acad. Sci. USA 76:666.

9. Fischli, W., A. Goldstein, M. Hunkapiller \& L. E. Hood. 1981. Two "big" dynorphins from porcine pituitary. Life Sci. 31:1769.

10. Kilpatrick, D. L., A Wahlstrom, H. W. LaHM, R. Blacker \& S. Udenfriend. 1982. Rimorphin, a unique, naturally occurring (Leu)enkephalin containing peptide found in association with dynorphin and alpha-neo-endorphin. Proc. Natl. Acad. Sci. USA 79:6480.

11. Watson, S. J., H. AKIL \& J. D. BarChas. 1979. Immunohistochemical and biochemical studies of the enkephalins, beta-endorphin and related peptides. In Endorphins in Mental Health Research. E. Usdin, W. M. Bunney \& N. S. Kline, Eds.:30-44.

12. ZAKARIAN, S. \& D. SMYTH. 1982. Beta-endorphin is processed differently in specific regions of rat pituitary and brain. Nature 296:250-252.

13. ZakARIAN, S. \& D. G. SMYTH. 1982. Review article: Distribution of beta-endorphin related peptides in rat pituitary and brain. Biochem. J. 202:561-571.

14. AKIL, H., E. YounG, S. J. WATSON \& D. CoY. 1981. Opiate binding properties of naturally occurring $N$ and $C$ terminus modified beta-endorphins. Peptides 2:289292. 
15. Deakin, J. F., J, O. Dostrovsky \& D. G. SMYTH. 1980. Influence of N-terminal acetylation and $\mathrm{C}$-terminal proteolysis on the analgesic activity of beta-endorphin. Biochem J. 189:501-506.

16. Evans, C. J., R. LoREnz, E. Weber \& J. D. BarChas. 1982. Variants of alphamelanocyte stimulating hormone in rat brain and pituitary: evidence that acetylated a-MSH exists only in the intermediate lobe of pituitary. Biochem. Biophys. Res. Commun. 106:910-919.

17. WALKER, J. M., H. AKIL \& S. J. WATSON. 1980. Evidence for homologous action of proopiocortin products. Science 210:1247-1249.

18. Walker, J. M., R. J. KaTz \& H. AKIL. 1980. Behavioral effects of dynorphin (1-13) in monkey and rat: Initial observations. Peptides 1:341-345.

19. Herman, B. H. \& A. Goldstein. 1985. Antinociception and paralysis induced by intrathecal Dyn-A. J. Pharm. Exp. Ther. 232(1):27-32.

20. Friedman, H. H., M. F. Jen, J. K. Chang, N. M. LeE \& H. H. Loh, 1981. Dynorphin-A possible modulatory peptide on morphine or B-endorphin analgesia in mouse. Eur. J. Pharmacol. 69:53-57.

21. Walker, J. M., H. MoISEs, D. CoY, G. Baldrighi \& H. AKIL. 1982. Non-opiate effects of dynorphin and Des-tyr-dynorphin. Science 218:1136-1138.

22. WAlkER, J. M., H. MoISES, D. COY, E. Young, S. WATSON \& H. AkJL. 1982. Dynorphin(1-17): lack of analgesia but evidence for non-opiate electrophysiological and motor effects. Life Sci. 31:1821-1824.

23. Walker, J. M., D. E. Tucker, D. H. Coy, B. B. Walker \& H. Akil. 1982. Des-Tyrosinedynorphin antagonizes morphine and analgesia. Eur. J. Pharmacol. 85:121-122.

24. PrZewlocki, R., G. T. Shearman \& A. Herz. 1983. Mixed opioid/nonopioid effects of dynorphin and dynorphin-related peptides after their intrathecal injection in rats. Neuropeptides 3:233.

25. Young, E. A. J. M. WALker, R. Houghten \& H. Akil. 1985. The breakdown of ${ }^{3} \mathrm{H}$ dynorphin $\mathrm{A}$ in vivo and in vitro. INRC Abstracts.

26. Weber, E., C. Evans \& J. D. Barchas. 1982. Predominance of aminoterminal octapeptide fragment of dynorphin in rat brain. Nature 299:77.

27. SeIzINGER, B., V. Hollt \& A. HERZ. 1981. Evidence for the occurrence of the opioid octapeptide dynorphin(1-8) in the neurointermediate pituitary of rats. Biochem. Biophys. Res. Commun. 102:197-205.

28. DORES, R. M. \& H. AKIL. 1985. Steady state levels of pro-dynorphin-related end products in the striatum and substantia nigra of the adult thesus monkey. Peptides. (In press.)

29. Corbett, A., A J. Patterson, A. T. McKnight, J. Magnan \& E. W. Kosterlutz. 1982. Dynorphin (1-8) and dynorphin (1-9) are ligands for the kappa subtype of opiate receptor. Nature 229:79.

30. Lewis, J. W., E. H. Chadler, J. T. Cannon \& J. C. Liebeskind. 1981. Hypophysectomy differentially affects morphine and stress analgesia. Proc. West. Pharmacol. Soc. 24:323-326.

31. AKIL, H., J. Madden, R. L. Patrick \& J. D. Barchas. 1976. Stress-induced increase in endogenous opiate peptides: Concurrent analgesia and its partial reversal by naloxone. In Opiates and Endogenous Opioid Peptides. H. W. Kosterlitz, Ed.:63-70. North Holland Publishing Co. Amsterdam.

32. MADDEN, J., H. AKIL \& J. D. BARChAS. 1977. Stress-induced parallel changes in central opioid levels and pain responsiveness in the rat. Nature 266:358-360.

33. LeWIS, J. W., J. T. CANNoN \& J. C. LIEBESKIND, 1980. Opioid and nonopioid mechanisms of stress analgesia. Science 208:623-625.

34. YounG, E. A. \& H. AKIL. 1985. CRF stimulation of ACTH/Beta-endorphin release: Effects of acute and chronic stress. Endocrinology 117:23-30.

35. ShIомi, H. \& H. AKIL. 1982. Pulse chase studies of POMC/beta-endorphin system in the pituitary of acutely and chronically stressed rats. Life Sci. 31:2185-2188.

36. AKIL, H., H. SHIOMI \& J. MATTHEWS. 1985. Induction of the intermediate pituitary by stress: Synthesis and release of a nonopioid form of beta-endorphin. Science 227:424-426. 
37. DORES, R. M., M. JAIN \& H. AKIL. 1986. Characterization of the forms of $\beta$-endorphin and $\alpha$-MSH in the caudal medulla of the rat and guinea pig. Brain Research. (In press.)

38. Li, C. H. et al. 1985. Fed. Proc.

39. Walker, J. M., A. Ghessari, B. A. Peters, S. J. Watson, N. Seidah, M. Chretien \& H. AKIL. 1986. Interactions among pro-opiomelanocortin products: modulation of pain sensitivity. In Neutrotransmitters and Pain. H. Akil \& J. Lewis, Eds. S. Karger-Verlag. Basel. (In press.)

40. ShIOMI, H., S. J. WATSON, G. KElSEY \& H. AkIL. 1986. A pre-translational and a posttranslational mechanism for regulating $\beta$-endorphin/ACTH cells: Studies in anterior lobe. Endocrinology. (Submitted for publication.)

41. YouNG, E., J. W. LEWIS \& H. AKIL. 1986. The preferential release of $\beta$-endorphin from the anterior lobe by corticotropin releasing factor. Peptides. (Submitted for publication.)

42. LEWIS, J. W., M. E. LewIS, D. J. LoOMUS \& H. AKIL. 1985. Acute systemic administration of morphine selectively increases mu opioid receptor binding in rat brain. Neuropeptides 5:117-120. 